Running head: INITIAL FIXATION POSITION IN CHILDREN

\title{
Visual and Linguistic Determinants of the Eyes' Initial Fixation Position in Reading Development
}

\author{
Stéphanie Ducrot ${ }^{1}$, Joël Pynte ${ }^{2}$, Alain Ghio ${ }^{1}$, and Bernard Lété ${ }^{3}$ \\ ${ }^{1}$ LPL, Aix-Marseille Université \& CNRS, France \\ ${ }^{2}$ CNRS \& Université Paris-Descartes, France \\ ${ }^{3}$ Laboratoire EMC \& University Lyon 2, Lyon, France
}

\section{Correspondence :}

Stéphanie Ducrot

Laboratoire Parole et Langage

Aix-Marseille Université \& CNRS

5 Avenue Pasteur

13100 Aix-en-Provence, France

Stephanie.Ducrot@univ-amu.fr 


\begin{abstract}
Two eye-movement experiments with one hundred and seven first- through fifth-grade children were conducted to examine the effects of visuomotor and linguistic factors on the recognition of words and pseudowords presented in central vision (using a variable-viewingposition technique) and in parafoveal vision (shifted to the left or right of a central fixation point). For all groups of children, we found a strong effect of stimulus location, in both central and parafoveal vision. This effect corresponds to the children's apparent tendency, for peripherally located targets, to reach a position located halfway between the middle and the left edge of the stimulus (preferred viewing location, PVL), whether saccading to the right or left. For centrally presented targets, refixation probability and lexical-decision time were the lowest near the word's center, suggesting an optimal viewing position (OVP). The viewing-position effects found here were modulated (1) by print exposure, both in central and parafoveal vision; (2) by the intrinsic qualities of the stimulus (lexicality and word frequency) for targets in central vision but not for parafoveally presented targets.
\end{abstract}

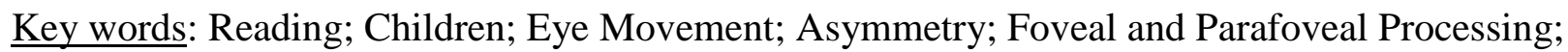


While a good deal of recent research has focused on the role of phonological skills in learning to perceive written language, little attention has been paid to developmental changes in the way visual information is extracted from print. However, reading is a visual task and limitations of the human visual system put strong constraints on the speed and the accuracy with which words can be recognized. For example, it has been found that reading proceeds quite normally when the fixated word disappears (Liversedge, Rayner, White, Vergilino-Perez, Findlay, \& Kentridge, 2004; Rayner, Liversedge, \& White, 2006; Rayner, Yang, Castelhano, \& Liversedge, 2011). In addition, in contrast to the large body of literature on skilled adult readers' eye movements, very little is known about children's oculomotor control during reading and how this develops with age (Rayner, 1998; but see Blythe \& Joseph, 2011). Basic aspects of oculomotor control (which provide optimal visual input) may play a crucial role in the development of reading skills. For example, the reader's eyes must land in the best position within the words to be read, the information being fixated must be extracted, a saccade must be programmed to position the eyes on the next word, and so on. The question that arises is whether adults and children differ in their saccade targeting strategies, specifically in terms of where words are first fixated in foveal and parafoveal vision.

Typically, the initial saccades of experienced readers land at the center of the word or slightly to the left, at the position called the preferred viewing location (PVL, McConkie, Kerr, Reddix, \& Zola, 1988; Rayner, 1979). This tendency is beneficial to the reader since the optimal viewing position (OVP) for initial fixation is located near the center of each word (O'Regan, LevySchoen, Pynte, \& Brugaillère, 1984; O’Regan, 1990). O'Regan et al. found that when the eyes fixate at the OVP, word identification is faster and more accurate. Also, the probability of correct identification of a word is the highest in this case (O'Regan, 1990). However, the eyes do not always work optimally during reading; they frequently undershoot and overshoot the word's OVP and sometimes even the word's boundary. This could be especially true with beginning readers. 
The present study examines the extent to which PVL and OVP develop during the elementary school years, whether or not PVP and OVP depend on visual and/or linguistic factors, and whether they are related to each other. First we review the main findings from past research that are relevant to the key manipulations of the present study, namely the effects of visual field (VF), viewing position (VP), and print exposure on reading.

\section{RVF Advantage in Parafoveal Processing}

One of the better-known asymmetries is the dominance of lexical processing associated with the left hemisphere (Bouma, 1973; Nicholls \& Wood, 1998). Specifically, word-identification, letter-identification, and lexical-decision latencies tend to be smaller and response accuracies greater when lexical stimuli appear in the right visual field (RVF) than in the left visual field (LVF). In addition, words are often recognized more accurately or faster than pseudowords, particularly in RVF, with a larger lexicality effect in RVF than in LVF (Iacoboni \& Zaidel, 1996; Jordan, Fuggetta, Paterson, Kurtev, Xu, 2011; Madrid, Lavie, \& Lavidor, 2010; Simola, Holmqvist, \& Lindgren, 2009). VF asymmetries are interpreted to reflect structural differences in the brain for language processing. According to this account, words presented to the RVF benefit from direct access to the left hemisphere, which for most individuals is dominant in language processing, while information presented to the LVF is processed first in the right hemisphere and thus requires interhemispheric transfer to reach the left hemisphere. Alternative views propose that an asymmetric distribution of attention to the VF (Hyönä \& Koivisto, 2006; Ducrot \& Grainger, 2007), or lowlevel perceptual learning resulting from long-term practice at reading in a certain direction (Nazir et al., 2004), contributes to VF asymmetries.

The fact that the beginnings of words are more informative than the endings (Brysbaert, Vitu, \& Schroyens, 1996) provides RVF words with an identification advantage. Moreover, in most Western languages, reading typically proceeds from left to right. This implies that words presented in the RVF are favored, because their initial letters appear closer to the right of the fixation point. In 
contrast, words presented to the LVF are at a disadvantage because attention must be shifted away in a direction that conflicts with the natural tendency to move the eyes from left to right. Although there are empirical discrepancies regarding this issue (see reviews in Brysbaert et al., 1996; Lindell, 2006), Battista and Kalloniatis (2002) have found support for the idea that the RVF advantage results from attending to a particular area of visual space as part of the normal reading habit, rather than from an innate superiority for word recognition in the RVF. In a similar vein, Nazir et al. (2004) showed that words presented in the RVF are processed faster and more accurately, because in left-to-right reading, the landing-site distribution of saccades is skewed, with its maximum to the left of the word's center (Brysbaert \& Nazir, 2005; McConkie et al., 1988; Vitu, O’Regan, \& Mittau, 1990), and thus words are more often processed in the RVF than in the LVF, resulting in perceptual learning for words ${ }^{1}$ presented in the RVF. It is thus possible that reading habits and hemispheric dominance are complementary, rather than incompatible - the contribution of brainspecialization mechanisms in the left hemisphere could be magnified due to left-to-right reading habits.

\section{VP Effects in Foveal and Parafoveal Vision}

Besides the RVF advantage in parafoveal processing demonstrated in the laterality research, there is another asymmetry of particular relevance to this study that has been widely studied in the eye-movement research. In sentence-reading experiments where eye movements are recorded by an eyetracker, the eye seems to land preferentially in positions slightly left of the middle of words (McConkie et al., 1988; Rayner, 1979; see also Reichle \& Laurent (2006) for consistent simulated landing-site distributions with artificial reading "agents"). For the French language, Vitu et al. (1990) reported that refixations during sentence reading were the least likely to occur for positions slightly left of the center. A similar finding was observed by these authors when words were presented in isolation, suggesting that there is a PVL slightly left of the center of words. But recognition performance for isolated words has also been found to be sensitive to fixation position, which strongly supports the advantage of an asymmetrical processing of verbal strings: when 
participants were forced by an experimental manipulation to fixate a stimulus word at a specific position, recognition performance was found to be the best for fixation positions left of the center (e.g., O'Regan et al., 1984; O'Regan \& Jacobs, 1992). This typical pattern of results is the OVP effect, which is characterized not only by the fact that performance is better when the center of a word is fixated rather than its edges, but also by an asymmetry in the resulting J-shape VP function. The effect arises from the rapid drop-off of visual acuity with retinal eccentricity and the fact that more letters from a word can be extracted when the eyes are near the word's center (Brysbaert \& Nazir, 2005; McConkie, Kerr, Reddix, Zola, \& Jacobs, 1989; but see also Lavidor \& Walsh, 2004 for a theoretical account). It may derive, in addition, from orthographic and lexical/morphological constraints associated with word identification (Deutsch \& Rayner, 1999; Farid \& Grainger, 1996; O’Regan et al., 1984; Stevens \& Grainger, 2003). The OVP emerges at the landing site that maximizes letter perceptibility and minimizes lexical ambiguity. This asymmetrical processing of written words has recently received a neurobiological account within the split-fovea theory. In order to reconcile eye-fixation behavior, lexical storage, and visual word recognition, the theory argues that in word reading, both VFs (including the fovea) are split, with everything to the left of the fixation projected to the right hemisphere, and reciprocally (Shillcock, Ellison, \& Monaghan, 2000). Accordingly, words are fixated more to the left, so that more letters will fall into the RVF and are thus projected to the left hemisphere, specifically devoted to verbal material.

Eye-movement and word-recognition data thus intersect to show that locations near the word center are optimal both for saccade targeting and foveal word processing. Most cognitive and oculomotor models assume that readers target the word center, i.e. the OVP, with their initial saccade (e.g., McConkie et al., 1988; Reichle, Rayner, \& Pollatsek, 2003; but see Vitu, 2003, who proposes that the eyes move forward with no specific saccade target) but the eyes are systematically deviated from this OVP. For McConkie et al. (1988, 1989), this difference between the OVP and the PVL is due to low-level visuomotor constraints inherent in the oculomotor system. It has been suggested, for instance, that readers might make an erroneous assessment of where the middle of 
the word actually is (Coëffé \& O'Regan, 1987; Ducrot \& Pynte, 2002). Alternatively, oculomotor noise could interfere with saccade computation and execution and lead to an aiming error (O'Regan \& Levy-Schoen, 1987; see also the notion of saccadic range error, McConkie et al., 1988, or Bayesian estimation of target positions, Engbert \& Krügel, 2010). According to Engbert and Krügel (2010), systematic error may arise from Bayesian estimation of the best saccade distance. ${ }^{2}$ Moreover, when a sentence is being read, each word appears surrounded by other words, and it has been suggested that, under such circumstances, the initial fixation position is the weighted center of several words (Coëffé \& O’Regan, 1987). But the leftward shift of the PVL (away from the OVP) could also be functional instead of being solely explained by oculomotor errors, and is related to parafoveal letter processing during fixations in reading. In continuous reading, when a reader fixates word $n$, information is obtained parafoveally about word $n+1$, which facilitates its subsequent (foveal) processing (Rayner, 1986, 1998) and could have an impact on what landing position readers consider optimal (for a discussion, see Radach \& McConkie, 1998; Rayner, Sereno, \& Raney, 1996).

Most relevant to the present study is the work by Brysbaert et al. (1996), who demonstrated a strong relationship between the OVP and PVL effects. According to this view, PVL reflects a tendency to optimize word processing. These authors argued that there is no fundamental difference between foveal and parafoveal vision, and that common mechanisms (one of which is the cerebral lateralization of language) underlie the off-center VP function both in foveal and parafoveal word recognition (for similar findings, see also Hunter \& Brysbaert, 2008). In both conditions, fixations to the left of the word's center are less damaging than fixations to the right, because attention can be allocated more rapidly and effectively to the right than to the left in people trained to read in that direction (see also Ducrot \& Grainger, 2007). In the same vein, Nazir (2000, 2003) assumes a strong relationship between OVP and PVL. According to her account, perceptual biases arise from perceptual learning, and frequently fixated positions are becoming optimal for word recognition. In that sense, the PVL is predictive of the OVP. In this line of reasoning, it is important to note that the 
OVP, like the PVL (and thus the RVF advantage), is dependent on reading habits (both are right of center for languages read from right to left; Deutsch \& Rayner, 1999). This can be seen as an argument that relates the two phenomena. It is unclear, however, how these results from isolated word-recognition studies generalize to normal reading. It needs to be examined whether there is a correlational or even causal relationship between OVP and PVL in continous reading.

\section{Reading, Eye Movements, and Print Exposure in Children}

Previous eye-movement studies have shown that the amount of information that can be extracted during a single eye fixation in reading is tightly linked to the development of reading skill. In support of this claim, Rayner (1986) found that when reading skill improves, the amount of information that can be extracted during a single fixation increases as well. In particular, he found that increased reading skill goes hand in hand with the ability to extract more information about the length and the letters of words to the right of the fixation location. A consistent finding is that beginning or less-skilled readers' perceptual spans are about 3-4 characters smaller than those of experienced readers (Häikiö, Bertram, Hyönä, \& Niemi, 2009; Rayner, 1986). This smaller span is generally understood to be a function of the amount of resources required for processing the fixated word (e.g., Rayner, Slattery, \& Bélanger, 2010) and can be related to lexical quality, because lowquality words - those that must be processed in a constituent-based manner - require greater processing resources than high-quality (lexicalized) words.

But the importance of phonological and orthographic skills in learning to read shouldn't overshadow the fact that a written or printed word is, above all, a visual stimulus, and perceptual and oculomotor skills (which provide optimal visual input) may play a crucial role in successful reading development. As a child progresses from being a beginning to a skilled reader, he/she becomes increasingly familiar with the printed form of letters within words, and then words within sentences. The ability to uptake visual information from the page is a crucial skill, insofar as the visual encoding of words forms a gateway to the higher-level linguistic processing associated with 
reading. While skilled readers recognize most words during one single fixation, beginning readers make multiple fixations within the same word (McConkie, Zola, Grimes, Kerr, Bryant, \& Wolff, 1991; Rayner, 1986). Additionally, the average number of fixations on a word and the percentage of words receiving multiple eye fixations decrease as reading skills improve. This steady drop in refixation frequency indicates developmental changes in children's ability to use available visual information from the word (McConkie et al., 1991; Rayner, 1986). Whitney and Cornelissen (2005) recently proposed a theoretical account of the development of orthographic-information extraction from print. They applied the SERIOL model $^{3}$ of proficient orthographic processing (Whitney, 2001) to reading acquisition. This model specifies how an abstract letter-position coding scheme is extracted from print and further used to activate lexical information. A key assumption of the model is the serial encoding of letter order by means of the input of a left-to-right activation gradient on letter nodes. In this framework, becoming a proficient reader requires the acquisition of this left-toright gradient. According Whitney and Cornelissen (2005), the beginning reader has to learn to fixate near the center of the word and invoke a locational gradient (first by attentional control, and then gradually by a bottom-up activation gradient) in order to maintain the sequential order of the letters.

\section{Present Study}

The present study provides a further contribution to the study of the visuomotor and linguistic determinants of the eyes' initial fixation position in reading development. In order to investigate the changes taking place during the elementary school years, we tested elementary school children of each grade (1st to 5th in France) in the two experiments presented in the paper. Because parafoveal processing in reading and VF and VP differences in visual word recognition have been extensively studied separately, we wanted to find a way to combine single-word paradigms and eye-tracking recording in a developmental approach. In the study, we presented words and pseudowords to the left or right of a central fixation point, and children were asked to make a lexical decision. The experiments described below were also devised to further investigate 
the relationship between the PVL and OVP effects. This was done using two conditions. In one condition (parafoveal presentation, Experiment 1), targets were shifted left or right of the central fixation point; in the other condition (central presentation, Experiment 2), fixation was on one of the five possible letter positions (achieved using a variable-position technique) (see Figure 1).

\section{EXPERIMENT 1}

The purpose of this experiment was to investigate the development of the PVL effect for words and pseudowords, presented to the LVF or the RVF in parafoveal vision.

\section{Method}

Participants. One hundred and seven first- through fifth-grade children participated in the experiment. They were native speakers of French, right-handed, and had normal or corrected-tonormal vision; none suffered from any neurological, psychiatric, or emotional disorders or were educationally disadvantaged. The children were recruited in three elementary schools located in Puyricard, a city in southern France, with their parents' informed consent and the agreement of the board of education. Twenty-seven of the children were first graders (12 females; mean age 6.8 years; range 6.2 to 7.3), 24 were second graders (11 females; mean age 7.7 years; range 7.0 to 8.3), 17 were third graders (11 females; mean age 8.5 years; range 8.1 to 9.0), 12 were fourth graders (6 females; mean age 9.9 years; range 9.5 to 10.4), and 27 were fifth graders (14 females; mean age 10.10 years; range 10.2 to 12.0 ). To ensure the representativeness of our sample, we tested the reading ability of all of the children using the standardized French reading test "L'Alouette" (Lefavrais, 1965). The Alouette test is commonly used in France to evaluate reading proficiency in terms of both word and non-word decoding and reading speed. The test is specifically designed to assess proficiency at rapidly switching between lexical and non-lexical processing during text reading. No contextual support is provided, and the order of the words in the text is unusual for French, making this test a test of decoding skill. The text contains 265 words, ranging from common words to rarely used ones. Participants are instructed to read the text as fast and as 
accurately as possible. Standardized reading scores are computed by combining speed (how many words were read during a period of three minutes) and accuracy (reading errors being taken into account). The mean reading age in first grade ( $M=6$ years 9 months, $S D=9$ months), second grade ( $M=7$ years 8 months, $S D=8$ months), third grade $(M=8$ years 6 months, $S D=8$ months), fourth grade $(M=9$ years 6 months, $S D=9$ months), and fifth grade $(M=10$ years 5 months, $S D=$ 9 months) did not differ significantly from the corresponding chronological age $(t \mathrm{~s}<1)$. Since we were interested in normal reading development, children who were considered by their teachers as either having specific learning deficits (i.e., the children with poor reading skills) or behavioral difficulties (i.e., children who exhibited attentional or other behavioral problems in class) were not included in the sample. All but three children were right-handed. Participants were tested between April and June, that is, at the end of the school year.

Materials, design, and stimuli. A total of 120 five- and six-letter linguistic stimuli were used. In order to test for the influence of lexical-access processes, the linguistic stimuli consisted of 60 words and 60 pseudowords. The words were selected from the first-grade lemma lexicon of Manulex ${ }^{4}$ (Lété, Sprenger-Charolles, \& Colé, 2004). Half of the words had a low frequency (LF) that is, a mean printed frequency of 16 occurrences per million - and the other half were high frequency (HF), with a mean printed frequency of 419 occurrences per million. In each frequency set, $93 \%$ of the words were nouns, $4 \%$ were verbs, and $3 \%$ were adjectives. For the pseudowords, the orthographic regularity of all trigrams was controlled (Content \& Radeau, 1988). These stimuli were presented at a distance of $1.25^{\circ}$ to the left or right of a central fixation cross (LVF or RVF). This experiment manipulated grade $\left(1^{\text {st }}, 2^{\text {nd }}, 3^{\text {rd }}, 4^{\text {th }}\right.$, and $\left.5^{\text {th }}\right)$, stimulus type (words and pseudowords), and VF (LVF and RVF) in a 5 × 2 × 2 factorial design. All factors except grade were manipulated within participants.

Apparatus and procedure. All children were tested individually at their schools. Eye movements were collected by a mobile infrared, head-mounted eye tracker (Eyelink 2, SR Research Ltd., Canada). The recording was based on infrared-light reflection from the pupil and cornea at a 
sampling rate of $250 \mathrm{~Hz}$. Although participants read binocularly, only the right eye was tracked, at a spatial resolution of less than $0.04^{\circ}$. A chin-and-forehead rest was used to minimize head movements. Prior to the experiment, the eye-tracker was calibrated using a 9-point calibration grid that extended over the entire computer screen. Before each trial, the calibration was checked by presenting a fixation point in the center of the screen; if needed, the calibration was automatically corrected. The eye tracker was interfaced with a Dell D-type docking station and a Dell Latitude D600 laptop computer. The target words were displayed in white lowercase letters against a black background in 24-point Courier New font ${ }^{5}$, using a 14-inch color monitor, at a resolution of 1024×768. Participants were seated $60 \mathrm{~cm}$ from the screen. At this distance, one letter subtended a visual angle of $0.5^{\circ}$.

Each trial consisted of the following sequence of events (see Figure 1). At the beginning of each trial, participants had to fixate the fixation cross displayed in the middle of the screen without moving their eyes. The importance of maintaining eye fixation on this point was stressed repeatedly according to the child's needs. Five-hundred ms later, the fixation point was replaced by a letter string that remained on the screen until the participant responded ${ }^{6}$. The letter string was displayed on the right or left of the fixation point, in such a way that the nearest character in the stimulus was located 2.5 characters away from the fixation point. Participants had to decide as quickly and accurately as possible whether or not the stimulus was a French word, and then press the corresponding button (right button for yes, left button for no). After participants had made their response, the screen was cleared, and 500ms later, a new trial began. A 12-item practice session was held in advance. It was followed by a single experimental block of 120 trials composed of words and pseudowords. All participants were given a break halfway through the experiment, and additional breaks were given whenever required. The entire experiment lasted approximately half an hour for the $1^{\text {st }}$ and $2^{\text {nd }}$ graders and 20 min for the children in the higher grades. 
The eye-tracking data were analyzed using customized software scripts written in $\mathrm{C}++$ (Emaa software package: Ducrot, Lété, Descottes, Muneaux, \& Ghio, 2006). The following eyemovement measures were computed: latency (the duration of fixation on the cross before making a saccade), saccade size (the size of the initial saccade), refixation probability (the probability of making an additional fixation within the word before leaving it), and lexical-decision time.

\section{Results and Discussion}

Fixations and saccades interrupted by blinks were excluded from further analysis. Fixations less than $80 \mathrm{~ms}$ were also deleted from the data set (i.e., 3.6\%). For nearly all trials, the participants moved their eyes toward the stimulus, either left or right, before performing the lexical decision task. Only data from correct responses were analyzed. The error data produced no effects of interest and showed no signs of a speed-accuracy tradeoff. Again, the question of interest in the present study was whether the size of these initial saccades was affected by the children's grade, the type of stimulus, and the side of presentation. The results are summarized in Table 1. Saccade direction was coded as a negative number for left presentations and as a positive number for right presentations. Landing position was measured relative to stimulus beginning (left edge). Lexical decision time was measured from string appearance to a button press. For the analysis, 5.33\% of the trials were discarded because of a lack of eye movement, an initial saccade triggered in the wrong direction, or a change in the recorded position of the eye while the participant was looking at the fixation point (since a head movement was suspected in this case). Regarding lexical decision time, any response that was more than three $S D$ s above the participant's mean was removed (see Balota et al. 2007, for an identical trimming procedure). Outliers accounted for $6.7 \%$ of the responses. The proportion of outliers in each grade and in each word type (words vs pseudowords) was equally distributed, ranging between $6 \%$ and $7.5 \%$.

Analyses of variance (ANOVAs) were first conducted using the following design: a 3 (participant group ${ }^{7}: 1^{\text {st }}$ grade, $2^{\text {nd }}-3^{\text {rd }}$ grades, and $4^{\text {th }}-5^{\text {th }}$ grades) $\times 2$ (presentation side: LVF and 
RVF) x 2 (type of target: words and pseudowords). For word analyses, word frequency was included.

\section{Insert Table 1 about here}

Saccade size. As in Ducrot \& Pynte (2002), saccade amplitude, rather than landing position, was chosen here as the main dependent variable in order to allow for small saccade-size changes that might not have been picked up in the letter-position metric being observed ${ }^{8}$. For all groups, there was a main effect of presentation side [left vs. right; $F(1,104)=169.08, p<.001]$. Saccades were longer for left presentation than for right presentation, regardless of the type of stimulus (word or pseudoword). The difference between words and pseudowords was not significant $(F<1)$. This effect corresponds to the children's apparent tendency, for peripherally located targets, to reach a position located halfway between the middle and the left edge of the stimulus, whether saccading to the right or left. Note that for right-to-left initial saccades, the landing positions clustered very close to the word center. There was no interaction between presentation side and group, $(F<1)$ but there was a main effect of participant group. Mean saccade amplitude increased from 3.76 letter units $(S D=0.84)$ in grade 1 to 3.93 in grades 2 and $3(S D=0.85)$ and went up to 4.19 letter units $(S D=$ 0.97 ) in grades 4 and $5,[F(2,104)=3.997, p=.037]$. When translated in terms of landing position, this effect corresponded to the fact that the mean landing position was located left of center for both left and right presentations, but only for the oldest children (Grades 4 and 5). Note that the separate word analyses revealed no effect of word frequency on saccade size $\left[F_{\mathrm{S}}<1\right.$ for word frequency only and for its interaction with presentation side].

Saccade latency. Presentation side and group affected the latency of the initial saccade. The ANOVA revealed a main effect of presentation side $[F(1,104)=11.164, p=.0012]$, regardless of the stimulus type (word or pseudoword, $F<1$ ) or frequency (HF vs. LF for the word analyses, $F<$ 1). Latencies of saccades triggered in the RVF (167 ms, $S D=22)$ were shorter on average than those of saccades directed at the LVF $(172 \mathrm{~ms}, S D=21)$. There was also a main effect of 
participant group $[F(2,104)=24.726, p<.0001]$, showing that latencies were longer for Grade 1 $(190 \mathrm{~ms}, S D=31)$ than for Grades 2-3 (172 ms, $S D=19)$ and Grades 4-5 (149 ms, $S D=15)$. Note that the mean saccade latencies were surprisingly short, but this can be explained by the fact that (a) there was only one saccadic target present at a time, and (b) the letter strings were positioned at an equal distance to the left and right of the fixation point.

Refixation probability. There was a main effect of stimulus type on the probability of making a second fixation on the target, $[F(1,104)=56.943, p<.001]$, with children making more refixations on pseudowords $(87 \%, S D=18)$ than on words $(79 \%, S D=22)$. There was a reliable effect of participant group on the probability of making a refixation, $[F(2,104)=11.309, p<.001]$ : mean refixation probability decreased from $93 \%(S D=10)$ in Grade 1 to $81 \%$ in Grades $2-3(S D=$ $20)$, and went down to $72 \%(S D=20)$ in Grades 4-5; all three participant groups differed significantly from each other [all $t \mathrm{~s}>2$, all $p \mathrm{~s}<0.02$ ]. Interestingly, the analyses revealed a significant presentation-side by lexicality interaction $[F(1,104)=4.722, p=.03]$, with an RVF advantage limited to word recognition. Pairwise comparisons revealed a significant difference between RVF and LVF for words only $[F(1,104)=4.109, p=.04$ for words, and $F<1$ for pseudowords]. There was also a presentation-side by grade interaction $[F(2,104)=3.35, p=.05]$, with a smaller adverse effect of fixating the LVF among the oldest children as compared to the other groups (the difference between $1^{\text {st }}$ graders and $2^{\text {nd }}-3^{\text {rd }}$ graders was nonsignificant). Note that for the word analyses, there was a main effect of word frequency $[F(1,104)=49.357, p<.001]$, with children making more refixations on LF words $(83 \%, S D=22)$ than on HF words $[75 \%, S D=$ 23]. This factor did not interact with presentation side $[F<1]$ or grade $[\mathrm{F}(2,104)=2.34, n s]$.

Lexical-decision time. For all groups, there was a main effect of presentation side [left vs. right; $F(1,104)=4.656, p=.03]$. Lexical-decision time $(\mathrm{LDT})$ was longer for left presentation (2040 ms, $S D=527)$ than for right presentation $(2000 \mathrm{~ms}, S D=531)$. The analysis of lexical decision times also revealed a significant main effect of stimulus type [words vs. nonwords; $F(1,104)=246.002, p<.001]$ and a stimulus-type by presentation-side interaction 
$[F(1,104)=5.809, p=.0177]$. Similar to what has been found on adult lateralized lexical decision tasks (e.g. Hyönä \& Koivisto, 2006), while words were processed more quickly than pseudowords (1797 vs. $2244 \mathrm{~ms}$ ), this effect was greater in the RVF than in the LVF (with a 489-ms difference in the RVF and a 405-ms difference in the LVF). Again, there was a main effect of participant group on this measure $[F(2,104)=87.326, p<.001]$, showing that lexical decision time was longer for Grade $1(3146 \mathrm{~ms}, S D=517)$ than for Grades 2 and $3(2066 \mathrm{~ms}, S D=334)$ than for Grades 4 and 5 $(1276 \mathrm{~ms}, S D=227)$. For the target-word analyses, there was a main effect of word frequency $[F(1,104)=255.446, p<.001]$ and a word-frequency by grade interaction $[F(2,104)=16.151$, $p<.001]$. Critically, while HF words $(1619 \mathrm{~ms}, S D=468)$ were processed more quickly than LF words were $(1948 \mathrm{~ms}, S D=475)$, the effect was smaller for the oldest children (with a 179-ms difference for Grades 4-5 vs. a 413-ms difference for the other groups; the difference between $1^{\text {st }}$ graders and $2^{\text {nd }}-3^{\text {rd }}$ graders was nonsignificant). No other interaction approached statistical significance.

There were main effects of participant group on all measures. The youngest children made shorter saccades associated with longer latencies, had higher refixation probabilities, and had longer lexical-decision times than the oldest ones. These effects represent basic changes in oculomotor behavior during reading that reflect the cognitive-processing difficulty associated with the reader's age and skill (Rayner, 1998). In addition, VF, lexicality, and word-frequency effects were obtained for all groups on refixation probability and lexical-decision time. We replicated the standard RVF advantage for languages with print that is read from left to right (for developmental data, see Iacoboni \& Zaidel, 1996; Siéroff \& Riva, 2010), and we replicated the larger lexicality effect in the RVF than in the LVF (Iacoboni \& Zaidel, 1996; Jordan et al., 2011; Madrid et al., 2010). Note that there was no evidence at all that frequency differentially affected the processing of words presented to one VF rather than the other. Most important is the finding that the initial-landing-position effect classically found for adults holds for children as young as age 6. We found no differences in the PVL when the target was a word vs. pseudoword or HF word vs. LF word. The most important 
result of this first experiment is the asymmetry found for all groups in the saccade size for left and right presentations.

\section{EXPERIMENT 2}

The second experiment focused on investigating the extent to which attentional factors, lexical factors, and print exposure influence within-word eye behavior, and more specifically the OVP effect. Experiment 2 followed the same procedure as in Experiment 1 except that within-word fixations and lower levels of eccentricity were used (using a variable-viewing-position technique).

\section{Method}

Participants. The participants were the same as in Experiment 1 (except six participants who were absent for the second experimental session).

Stimuli, design, apparatus, and procedure. The design and stimuli were the same as in Experiment 1 except that the targets were presented foveally, using a variable-viewing-position technique (see Figure 1). Each stimulus was divided into five equally-wide zones (i.e., one letter wide for a five-letter stimulus and 1.2 letters wide for a six-letter stimulus). Stimuli were presented in such a way that participants initially fixated the center of each zone (hereafter called positions P1, P2, P3, P4, and P5). Across all participants, each word was seen from all five fixation positions. As in Experiment 1, participants were first instructed to look at a fixation point at the beginning of each trial, and not to move their eyes. After $500 \mathrm{~ms}$, the fixation point was replaced by a target that was displayed on either side of the fixation point, according to the position condition. Participants had to decide as quickly and accurately as possible whether or not the stimulus was a French word (right button for yes, left button for no). Analyses of variance (ANOVAs) were conducted using the following design: 3 (participant group: $1^{\text {st }}$ grade, $2^{\text {nd }}-3^{\text {rd }}$ grades, and $4^{\text {th }}-5^{\text {th }}$ grades) x 5 (fixation position: P1, P2, P3, P4, and P5) x 2 (type of stimulus: words and pseudowords). For the word analyses, word frequency was included.

\section{Results and Discussion}


The following eye-movement measures were computed: refixation probability (the probability of making a second fixation within the word before leaving it), refixation-saccade size (the size of the corrective saccade, reflecting the distance covered by the eyes while they move from the first to the second position within the word), and lexical-decision time. The analyses conducted were the same as in Experiment 1. Fixations less than $80 \mathrm{~ms}$ were deleted from the data set (i.e., 3.1\%). The data were analyzed only for those cases in which the participant's response was correct and when the decision time fell within three $S D s$ of that participant's overall mean, leading to the rejection of $7.2 \%$ of the responses. The proportion of outliers was equally distributed across grades and word types (words vs pseudowords), ranging between $6 \%$ and $7.5 \%$. Note that the correct-identification percentages indicated a significant main effect of participant group $[F(2,98)=42.28, p<.001]$, with the mean percentage of correct word identifications for 1st graders (79\%) differing from those for the other grades $(94 \%)$ and a main effect of word frequency in the word analyses $[F(1,96)=95,716$, $p<.001$ ], with better performance for HF words $(94.5 \%)$ than for LF words $(83 \%)$.

\section{Insert Table 2 about here}

Refixation probability. The pattern of results is extremely clear here. The analyses of variance showed that the effect of initial-fixation position on refixation probability was consistently significant for all groups $[F(4,392)=67.108, p<.001]$. As can be seen in Figure 2, the location in the words where the refixation curves dropped to their minimums was to the left of the target's center, thus suggesting an OVP. There was also a significant main effect of lexicality, with a higher refixation probability for pseudowords $(70 \%)$ than for words $(60 \%)$ and a lexicality by fixationposition interaction $[F(4,392)=10.439, p<.001]$. Whereas a J-shape function was observed for words, with a difference between fixating at the beginning and the end of the word (11\%), a symmetrical curve was found for pseudowords (1\%). An ANOVA limited to positions P1 and P5 confirmed this result, with a significant interaction between position and lexicality, $F(1,98)=$ $10.465, p=.0017$. The analyses also revealed a significant effect of group $[F(2,98)=24.275, p<$ 
$.001]$ : the overall refixation rate was much lower for the oldest participants $(50 \%)$ than for the $1^{\text {st }}$ graders $(86 \%)$ and $2^{\text {nd }}-3^{\text {rd }}$ graders $(70 \%)$. There was also a significant fixation-position by participant-group interaction $[F(8,392)=5.504, p<.001]$, with a lower fixation-position advantage for the first graders $[F(4,392)=4.72 p=.0019]$ as compared with the older children $[F(4,392)=$ $32.13, p<.001$, and $F(4,392)=58.816, p<.001$, for Grades $2-3$ and Grades 4-5, respectively]. For the word analyses, there was a main effect of word frequency $[F(1,91)=66.347, p<.001]$, with HF words $[52 \%, S D=33.4]$ being refixated less than $\mathrm{LF}$ words $(64 \%, S D=34.1)$. This effect appeared to be slightly stronger for the word-initial and word-final positions than for positions P2P3; this is consistent with the existence of a marginally significant frequency by initial-fixationposition interaction $[F(4,364)=2.045, p=.08]($ see O'Regan \& Jacobs, 1992, Experiment 1, for a similar result).

Refixation-saccade size. Initial-fixation position had a main effect $[F(4,392)=730.784$, $p<.0001$ ], regardless of stimulus type (words or pseudowords, $F<1$ ) and frequency (HF vs LF for the word analyses, $F<1$ ), thus reflecting the fact that the saccade size was larger at unfavorable positions (P1, P4-P5, 1.6 letter units, $S D=0.6)$ than for positions near the middle of the stimulus (P2-P3, 0.4 letter units, $S D=0.6$ ). There was also a significant main effect of participant group $[F(2,98)=6.077, p=.0033]$. Mean saccade amplitude decreased from 0.5 letter units $(S D=1.2)$ in Grade 1 to 0.39 units in Grades 2-3 $(S D=1.3)$ and to 0.22 units $(S D=1.4)$ in Grades 4-5 $[F(2,104)$ $=3.997, p=.037]$.

Lexical-decision time. The analyses indicated that for all grades, the position of the initial fixation had a substantial effect on the lexical decision times $[F(4,388)=19.97, p<.001]$ : LDT was always shorter when the eyes initially fixated slightly left of the middle of the word. There were also significant effects of lexicality $[F(1,97)=138.509, p<.001]$ and participant group $[F(2,97)=86.244, p<.001]$, and a significant lexicality by group interaction, showing that words were responded to faster than were pseudowords, and that the response-time difference for words and pseudowords was larger for the youngest readers $[F(2,97)=17.662, p<.001]$. Most 
importantly, as observed for refixation probability, the effect of initial-fixation position interacted with the lexical status of the letter string $[F(4,388)=10.901, p<.001]$, thus confirming the existence of an optimal viewing position in word recognition only. The effect of word frequency shows up clearly in the data $[F(1,91)=133.095, p<.001]$ : for every participant group, the LF curve was above the corresponding HF curve. This factor interacted with group $[F(2,91)=15.936, p<$ $.001]$, with a larger frequency effect for the youngest children $(865 \mathrm{~ms})$ than for the $2^{\text {nd }}-3^{\text {rd }}$ graders $(245 \mathrm{~ms})$ and the $4^{\text {th }}-5^{\text {th }}$ graders $(179 \mathrm{~ms})$, but it did not interact with initial-fixation location $[F<1]$. This suggests that with the development of reading skill, lexical decisions become increasingly based on a lexical reading strategy performed by means of a quick familiarity check in the orthographic lexicon.

\section{Insert Figure 2 about here}

As Figure 2 demonstrates, and in agreement with other research (e.g., Nazir et al., 2004; Shillcock, 2007), the effects of initial fixation were limited here to word recognition (but see Hutzler et al., 2008, for different results among adults). The above analyses show that the initial landing position in a word strongly affected the within-word behavior for all grades considered. First, as previously reported for adults (McConkie et al., 1989), there was a refixation OVP effect such that the likelihood of refixating a word was smaller when the eyes initially fixated just left of the middle of the word. This left-half advantage reflects RVF superiority, a finding previously obtained in languages written from left to right. As in McConkie et al. (1989), the refixation-OVP curve was affected by word frequency: lexical information seems to help more when VP conditions are poor, thus suggesting that OVP effects are partly determined by lexical processing ${ }^{9}$. Second, LDT and response accuracy also showed effects of the initial-fixation position in the word. All of the curves have their minimum either at the word's middle or just to its left. Finally, wordfrequency and lexicality effects were obtained for all groups on LDT and refixation rates. These effects were modulated by grade. Our findings for children with varying reading levels, and the 
results obtained for adults in other studies, suggest that lexical decisions are based on the orthographic lexicon to an increasing extent as reading skill develops.

\section{CROSS-EXPERIMENT ANALYSIS}

The average OVP of centrally presented words (defined here as the optimal viewing position for performing the lexical decision task, that is the position where the probability of making a second fixation within the word before leaving it was the smallest, overall mean $=2.19$ letter units) was very similar to the initial landing positions in the parafoveal experiment $(2.27$ and 2.79 letter units for the RVF and LVF, respectively). An additional analysis combining Experiment 1 (parafoveal presentation of targets) and Experiment 2 (central presentation of targets) was thus carried out in order to further investigate the relation between individual landing position and OVP. Every participant who had taken part in both experiments was assigned an OVP index (the position where his/her refixation probability was the lowest, Position 1, 2, 3, 4 or 5) and a PVL index (his/her mean initial-landing position in the RVF). The correlation between these two measures was nonsignificant $[r(99)=-0.074, n s]$. The same tendency was found for initial-landing positions in the $\operatorname{LVF}[r(99)=-0.0601, n s]$. Although the individual OVP's and landing positions looked very similar, critically, they were not correlated. This result is in line with results reported for adults by Radach, Reilly and Vorstius (2004).

\section{GENERAL DISCUSSION}

The aim of the present study was twofold. First, we wanted to investigate the positioning of saccadic eye movements in terms of where linguistic stimuli are first fixated when children are processing isolated words and pseudowords in foveal and parafoveal vision. Secondly, we wanted to find out how their lexical knowledge interacts with visual information intake, and to what extent this interaction facilitates word recognition. The roles of top-down and bottom-up processing in word recognition were examined by studying the degree to which reading behavior is affected by manipulations of the VP (in the fovea and parafovea), by the intrinsic qualities (lexicality and word 
frequency) of the stimulus, and by the amount of experience with print (first- to fifth-grade children). In what follows we discuss four main aspects of our results.

\section{Visual Determinants in Saccade Targeting}

For all groups of children, stimulus location had a strong effect on the parameters of basic oculomotor behavior and lexical-decision time, in both central and parafoveal vision. VF asymmetries comparable to those observed with adults were evident by the end of the first year of reading instruction. The results of the first experiment suggested the existence of an asymmetry in the size of saccades launched toward isolated words and pseudowords lying either to the right or to the left of an initial fixation point, with left-going saccades being about one character longer. This is consistent with the finding that, for peripherally located targets, children apparently tend to reach a position located halfway between the middle and the left edge of the stimulus (PVL), whether saccading to the right or left, and suggests that some of the factors responsible for the PVL effect are also at work in single-word targeting. When fixated in this location, most of the orthographic information needed to identify the word is located in the reading direction. The present data demonstrate that French first graders develop their reading skills rapidly, and in some respects, it seems that the oculomotor system at that level is already well prepared for the task of guiding the eyes (McConkie et al., 1991; Huestegge et al., 2009). This conclusion provides empirical support for Reichle and Laurent's reinforcement learning model, in which “intelligent” eye movements, including fixating close to the word center, emerge quickly during learning (Reichle \& Laurent, 2006).

Previous eye-movement research has established that when the eyes first fixate a nonoptimal spot for word recognition (word beginning or end), it makes sense to exit early from the non-optimal spot and program a saccade to a more optimal location in the word. In the second study, we found evidence, for all grades, of such eye behavior while children processed isolated words in central vision. The probability of making a refixation in the target word increased when the initial fixation was imposed on the word beginning rather than to the left of the word center, 
leading to a refixation OVP effect (Vitu et al., 2001). This effect translated also into an analogous effect on LDT. It is generally assumed that the main cause for the refixation OVP effect lies in the very strong decline in visual acuity, even within the fovea (McConkie et al., 1989). The fundamental conclusion from this experiment is that the VP effect for isolated words is also influenced by the intrinsic qualities of the stimulus (lexicality and word frequency) and by print exposure. More specifically (1) there was no OVP effect for pseudowords, (2) LF words were less effectively processed at fixation points away from the OVP (O’Regan \& Jacobs, 1992; Ducrot \& Grainger, 2007), and (3) the OVP curve was more pronounced for older children.

\section{How Target Properties Affect the VP Asymmetry}

Word-frequency and lexicality effects on LDT were obtained for all groups, both in central and parafoveal vision. Similar to what has been found for adults in lateralized lexical decisions (e.g., Hyönä \& Koivisto, 2006), the data of Experiment 1 indicated a greater lexicality effect in the RVF compared to the LVF (see also Madrid et al., 2010) for all grades. In agreement with other research, Experiment 2 showed that the effects of initial fixation were restricted to word recognition (Nazir et al., 2004; Shillcock, 2007; but see Hutzler et al., 2008 for different results in adults). The finding that children apparently use different inspection strategies, depending on the type of stimulus being targeted (words vs. pseudowords), suggests that the off-centeredness observed for words does not result from oculomotor constraints alone.

Many cognitive theories of eye-movement control in reading (in particular the E-Z Reader model) emphasize the role of word frequency in word identification and saccade triggering (e.g., Reichle et al., 2003). In this framework, the following analyses were undertaken to examine the influence of word frequency on PVL (Experiment 1) and OVP (Experiment 2). Word frequency had no effect on landing position, thus suggesting that where the eyes land within a word is not influenced by ongoing linguistic processing. In addition, refixation probability for LF words was consistently higher than for HF words, with this effect being independent of initial landing position (LVF vs. RVF) (Figure 3a). 


\section{Insert Figure 3 about here}

We did, however, observe an interaction between word frequency and VP in Experiment 2 (central presentation of target words) (Figure 3b). The magnitude of the refixation-probability and the lexical-decision-time OVP effects was clearly greater numerically for LF than HF words. This is consistent with O'Regan and Jacobs's (1992) finding that the cost of not fixating the center of centrally presented target words was greater for LF words than for HF words (see also Ducrot \& Grainger, 2007; Montant et al., 1998). At the least optimal viewing positions on which visual information is most difficult to integrate, top-down feedback helps significantly to compensate for the poorer visual conditions. Related effects were also found by Pynte (1996), who varied the information distribution within a word. Fixations on inferior VPs within a word (i.e., at letter positions not removing the ambiguity between the target and lexical competitors) affected HF and LF words differently. Again, inferior fixation positions led to more refixations, especially in LF words. It can thus be argued that the frequency effect and its interactions with other variables increase as the quality of the presentation conditions, stimulus attributes, and/or participants' skills become poorer (see Ashby, Rayner, \& Clifton, 2005, for similar findings in adults, and Slattery \& Rayner, 2010, for a similar effect with text degradation). Furthermore, the absence of an interaction between word-frequency and VF effects in the parafoveal presentation conditions of Experiment 1 is consistent with the results reported by Iacoboni and Zaidel (1996), and Coney (2005). All of these studies reported a clear additivity between VF and word-frequency effects in lateralized presentation conditions. This is further evidence that VF effects obtained with foveal and parafoveal presentation of stimuli are at least partly driven by distinct mechanisms.

\section{Reading in the Fovea and Parafovea}

We found comparable RVF advantages for words at different retinal eccentricities (central or parafoveal vision) for all grades: word recognition was better in the RVF than in the LVF independent of target-word eccentricity (Battista \& Kalloniatis, 2002; Ducrot \& Grainger, 2007) 
and print exposure (Siéroff \& Riva, 2011). Our results are also in agreement with brain-imaging studies that find strongly lateralized activation in reading by the age of 6-7 years (Gaillard et al., 2003). The RVF superiority effect reflects the benefit of initial fixations on the beginning of the word. It is well known that the useful visual field is asymmetrical in reading, extending farther to the right for left-to-right languages such as English and French and farther to the left for right-to-left languages such as Hebrew (Pollatsek, Bolozky, Well, \& Rayner, 1981; Rayner, 1998). This is clearly relevant to the present discussion. If letters presented, say, on the right are perceived better than those presented on the left (which was presumably the case for our participants), fixating first to the left of the middle makes sense, since this is likely to enhance overall letter visibility (Nazir et al., 1991).

The fundamental conclusion from the OVP experiment is that the initial-fixation-location effect for words in isolation is influenced by several factors. The OVP may depend on fine tuning between word-specific lexical characteristics, viewing position, and print exposure. However, the demands of reading are such that the primary goal of the reader is to land somewhere near the middle of the word. But, as is the case with French, the eyes typically fall short of the word's center (in a systematic way), thus generating distributions of landing sites that yield the PVL. It is possible that for the majority of words in French, landing on the first part of the word gives the reader enough information to process the word effectively. As a result, readers may become accustomed to landing on a word's beginning, regardless of the actual structure of the word (as was suggested by the results of Experiment 1). Also, our results seem compatible with the perceptual learning account suggesting that long-term reading in a particular direction can result in VF differences (Nazir et al., 2004). The analysis of individual OVP and landing position correlations did not support this view, however. Although the average OVP estimated on the basis of refixation probability of centrally presented targets was very similar to the PVL in the parafoveal experiment, the individual means were not correlated (see Radach et al., 2004, for similar results). In all grades, the initial landing position in the parafovea experiment did not predict the position of the OVP observed in the fovea 
experiment, and vice versa. We can tentatively conclude that there is no evidence of the OVP being the "basis" for the PVL (Brysbaert et al., 1996) or the PVL being the "basis" for the OVP (Nazir, 2000).

\section{Developmental Trends}

Firstly, the VP effects found here were modulated by school grade, both in central and parafoveal vision. The results of the first experiment showed that first graders made shorter saccades and had higher numbers of refixations than did fifth graders, with initial landing positions located left of center for both left and right presentations only for the older children. In addition, Experiment 2 showed a smaller VP advantage for first-grade children compared with older children. One possible explanation for these results is related to oculomotor control as the source of difficulty; shifted initial landing positions and increased refixation rates may arise simply because beginning readers make shorter saccades, leaving them no option but to fixate to the left of the normal PVL in the RVF and to the right of the normal PVL in the LVF. In this vein, Lehtimäki and Reilly (2005) were able to show that it is possible to train young readers to control their eye movements during reading so that the saccades they make land at the OVP of each word. Another plausible explanation of the data is that the eye-movement strategy that a reader adopts is simply an affordance of the overall quality of his/her lexical representations (Kuperman \& Van Dyke, 2011; Rayner, 1998). Thus, a skilled reader who has full-form lexical representations available for the vast majority of words can use this information to guide eye movements by employing a reading strategy that directs the eyes towards the center of words, because this is the OVP for full-form word recognition. In contrast, beginning readers who are frequently forced to rely on sublexical processing to identify words will adopt a more careful eye-movement strategy with shorter saccades and multiple fixations on words. This suggestion is consistent with several studies attesting to smaller saccade sizes and increased refixation rates in poor, slow, dyslexic, and beginning readers

(e.g., Hawelka, Gagl, \& Wimmer, 2010; Huestegge et al., 2009; Kuperman, \& Van Dyke, 2011; Rayner et al., 2010). However, if the second account was the sole explanation, then why would 
beginning readers first fixate to the right of the middle of a left-presented word? In addition, as acuity drops rapidly with eccentricity, fixing to the right of the normal position runs the risk of placing the initial portion of the word in low-acuity, left-parafoveal vision. Rather, these results suggest that various saccade-related measures continue to develop throughout elementary school, and point out differences between the ages of six and eleven reflecting different oculomotor, perceptual, and cognitive constraints in beginning and expert reading.

Second, we observed classic lexicality and frequency effects on LDT and refixation rates, in central and parafoveal vision alike. Both effects were weaker in fourth and fifth grades, which might be explained in terms of a more automatic lexical access in older children, specifically for infrequent words. In contrast, the eye-movement recording of our beginning readers displayed clear indicators of effort, including greater sensitivity to lexicality and word frequency. This is consistent with a number of studies reporting that poor readers draw more benefit from HF words than do better readers in eye-tracking measures (e.g., Hawelka et al., 2010), and this is related to the wellestablished finding that novel or less familiar words elicit longer reading times than relatively familiar words (e.g. Williams \& Morris, 2004). While a number of accounts for this effect are possible, the most widely accepted explanation is that low decoding ability suggests poor-quality lexical representations, a consequence of a limited experience with written language. Word recognition for these readers must rely on sublexical processing. In contrast, readers with high decoding skills exhibited improved lexical access. For these readers, most words were read via automatic activation of well-specified lexical representations. Additional evidence has been obtained in eye-movement studies showing that the perceptual span is smaller in children than in adults (Häikiö et al., 2009; Rayner, 1986), even though children, like adults, are able to use parafoveal visual information to guide their saccades during sentence reading (Joseph et al., 2009). This difference in perceptual span is assumed to be related to reading skills. When reading a text, slower readers may allocate most of their attention to the foveal word, and their attention does not shift as efficiently and as far into the parafovea as is the case with faster readers, who process foveal 
words with greater ease and speed (but see Everatt et al., 2004, for a different view). All together, these results obtained from beginning readers indicate that nonoptimal reading skills are more likely to either increase frequency effects themselves or to increase frequency effects under particularly non-optimal stimulus or presentation conditions.

\section{Conclusion}

For all groups of children, stimulus location had a strong effect on the parameters of basic oculomotor development and lexical-decision time, in both central and parafoveal vision. VF asymmetries comparable to those observed with adults were evident by the end of the first year of reading instruction. The viewing-position effects were influenced by the intrinsic qualities of the stimulus (lexicality and word frequency) for targets in central vision but not for parafoveally presented targets; suggesting differences in the way printed words are processed in peripheral and central vision. Moreover, in all grades, the initial landing position in the parafovea experiment did not predict the position of the OVP observed in the fovea experiment, and vice versa. Apparently, there is no evidence for the OVP to be based on the PVL or for the PVL to be based on the OVP. From a developmental point of view, the VP effects found here were modulated by school grade, both in central and parafoveal vision; thus suggesting that various saccade-related measures continue to develop throughout elementary school, reflecting different oculomotor, perceptual, and cognitive constraints in beginning and expert reading. 


\section{REFERENCES}

Aghababian, V., \& Nazir, T. (2000). Developing normal reading skills: Aspects of visual processes underlying word recognition. Journal of Experimental Child Psychology, 76, 123-150.

Ashby, J., Rayner, K., \& Clifton, C., (2005). The reading patterns of highly-skilled and average readers: Evidence from eye movements. Quarterly Journal of Experimental Psychology: Section A, 58, 1065-1086.

Balota, D. A., Yap, M. J., Cortese, M. J., Hutchison, K. A., Kessler, B., Loftus, B., Treiman, R. (2007). The English lexicon project. Behavior Research Methods, 39, 445-459.

Battista, J., \& Kalloniatis, M. (2002). Left-right word recognition asymmetries in central and peripheral vision. Vision Research, 42, 1583-1592.

Blythe, H. I., Liversedge, S. P, Joseph, H., White, S. J., \& Rayner, K. (2009). Visual information capture during fixations in reading for children and adults. Vision Research, 49(12), 15831591.

Blythe, H. I., \& Joseph, H. (2011). Children's eye movements during reading. In S. Liversedge, I. Gilchrist, \& S. Everling (Eds.), Oxford Handbook on Eye Movements (pp. 643-662). Oxford: Oxford University Press.

Bouma, H. (1973). Visual interference in the parafoveal recognition of initial and final letters of words. Vision Research, 13, 767-782.

Brysbaert, M., \& Nazir, T. (2005). Visual constraints on written word recognition: Evidence from the optimal viewing position effect. Journal of Research in Reading, 28, 216-228.

Brysbaert, M., Vitu, F., \& Schroyens, W. (1996). The right visual field advantage and the optimal viewing position: On the relation between foveal and parafoveal word recognition. Neuropsychology, 18, 385-395.

Coëffé, C., \& O’Regan, J. K. (1987). Reducing the influence of non-target stimuli on saccade accuracy: Predictability and latency effects. Vision Research, 27(2), 227-240.

Coney, J. (2005). Word frequency and the lateralization of lexical processes. Neuropsychologia, 43, 142-148. 
Content, A., \& Radeau, J. (1988). Données statistiques sur la structure orthographique du Français. Cahier de Psychologie Cognitive, 4, 399-404.

Davis, C. J. (1999). The self-organising lexical acquisition and recognition (SOLAR) model of visual word recognition. Doctoral dissertation, University of New South Wales, Sydney, Australia.

Davis, C. J. (2010). The spatial coding model of visual word identification. Psychological Review, $117,713-758$.

Deutsch, A., \& Rayner, K. (1999). Initial fixation location effects in reading hebrew words. Language \& Cognitive Processes, 14, 393-421.

Ducrot, S., \& Grainger, J. (2007). Deployment of spatial attention to words in central and peripheral vision. Perception \& Psychophysics , 69(4), 578-590.

Ducrot, S., Lété, B., Descottes, C., Muneaux, M., \& Ghio, A. (2006). The Emaa (Eye Movement Acquisition and Analysis) software package. Unpublished Technical Report (67 p.), University of Provence.

Ducrot, S., \& Pynte, J. (2002). What determines the eyes' landing position in words? Perception \& Psychophysics, 64(7), 1130-1144.

Engbert, R., \& Krügel, A. (2010). Readers use Bayesian estimation for eye-movement control. Psychological Science, 21, 366-371.

Farid, M., \& Grainger, J. (1996). How initial fixation position influences visual word recognition: A comparison of French and Arabic. Brain \& Language, 53, 681-690.

Gaillard, W. D., Sachs, B. C., Whitnah, J. R., Ahmad, Z., Balsamo, L. M., Petrella, J. R., Braniecki, S. H., McKinney, C. M., Humter, K., Xu, B., \& Grandin, C. B. (2003). Developmental aspects of language processing: fMRI of verbal fluency in children and adults. Human Brain Mapping, 18, 176-185.

Gomez, P., Ratcliff, R., \& Perea, M. (2008). The overlap model: A model of letter position coding. Psychological Review, 115, 577-601.

Grainger, J., \& van Heuven, W. (2003). Modeling letter position coding in printed word perception. In P. Bonin (Ed.), The mental lexicon (pp. 1-24). New York: Nova Science. 
Häikiö, T., Bertram, R., Hyönä, J., \& Niemi, P. (2009). Development of the letter identity span in reading: Evidence from the eye movement moving window paradigm. Journal of Experimental Child Psychology, 102, 167-181.

Hawelka, S., Gagl, B., \& Wimmer, H. (2010). A dual-route perspective on eye movements of dyslexic readers. Cognition, 115, 367-379.

Huestegge, L., Radach, R., Corbic, D., \& Huestegge, S. M. (2009). Oculomotor and linguistic determinants of reading development: A longitudinal study. Vision Research, 49, 2948-2959.

Hunter, Z. R., \& Brysbaert, M. (2008). Theoretical analysis of interhemispheric transfer costs in visual word recognition. Language and Cognitive Processes, 23, 165-182.

Hutzler, F., Braun, M., \& Jacobs, A. M. (2008). On the specificities of the inverted-optimal viewing position effect and their implications on models of eye movement control during reading. Brain Research, 1239, 152-161.

Hyönä, J., \& Koivisto, M. (2006). The role of eye movements in lateralized word recognition. Laterality, 11, 155-169.

Iacoboni, M., \& Zaidel, E. (1996). Hemispheric independence in word recognition: Evidence from unilateral and bilateral presentations. Brain and Language, 53(1), 121-140.

Jordan, T. R., Fuggetta, G., Paterson, K. B., Kurtev, S., \& Xu, M. (2011). An ERP Assessment of Hemispheric Projections in Foveal and Extrafoveal Word Recognition. PLoS ONE, 6(9), e23957. doi:10.1371/journal.pone.0023957

Joseph, H., Liversedge, S. P., Blythe, H. I., White, S. J., \& Rayner, K. (2009) Word length and landing position effects during reading in children and adults. Vision Research, 49(16), 20782086.

LaBerge, D., \& Samuels, J. (1974). Towards a theory of automatic information processing in reading. Cognitive Psychology, 6, 293-323.

Kuperman, V., Van Dyke, J. A. (2011). Effects of individual differences in verbal skills on eyemovement patterns during sentence reading. Journal of Memory and Language, 65, 45-73.

Lavidor, M., \& Walsh, V. (2004). The nature of foveal representation. Nature Reviews Neuroscience, 5, 729-735. 
Lefavrais, P. (1965). Test de l'Alouette. Paris: ECPA.

Lehtimaki, T. M., \& Reilly, R. G. (2005). Improving eye movement control in young readers. Artificial Intelligence Review, 24(3-4), 477-488.

Lété, B., \& Fayol, M. (in press). Substituted and transposed-letter effects in a masked priming paradigm with French developing readers and dyslexics. Journal of Experimental Child Psychology.

Lété, B., Sprenger-Charolles, L., \& Colé, P. (2004). Manulex: A grade-level lexical database from French elementary-school readers. Behavior Research Methods, Instruments, \& Computers, $36,156-166$.

Lindell, A. K. (2006). In your right mind: Right hemisphere contributions to language processing and production. Neuropsychology Review, 16, 131-148.

Liversedge, S. P., Rayner, K., White, S. J., Vergilino-Perez, D., Findlay, J. M., \& Kentridge, R. (2004). Eye movements when reading disappearing text: Is there a gap effect in reading? Vision Research, 44(10), 1013-1024.

Madrid, G. J., Lavie, N., \& Lavidor, M. (2010). Asymmetrical perceptual load in lateralized word processing . European Journal of Cognitive Psychology, 22(7), 1066-1077.

McConkie, G. W., Zola, D., Grimes, J., Kerr, P. W., Bryant, N. R., \& Wolff, P. M. (1991). Children's eye movements during reading. In J. F. Stein (Ed.), Vision and visual dyslexia (pp. 251-262). London: Macmillan Press.

McConkie, G. W., Kerr, P. W., Reddix, M. D., \& Zola, D. (1988). Eye movement control during reading: I. The location of initial eye fixations on words. Vision Research, 28(10), 245-253.

McConkie, G. W., Kerr, P. W., Reddix, M. D., Zola, D., \& Jacobs, A. M. (1989). Eye movement control during reading: II. Frequency of refixating a word. Perception \& Psychophysics, 46, $245-253$.

Montant, M., Nazir, T., \& Poncet, M. (1998). Pure alexia and the viewing position effect in printed words. Cognitive Neuropsychology, 15, 93-140.

Nazir, T. A. (2000). Traces of print along the visual pathway. In A. Kennedy, R. Radach, D. Heller, \& J. Pynte (Eds.), Reading as a perceptual process (pp. 3-23). Oxford: Elsevier. 
Nazir T. A. (2003). On hemispheric specialization and visual field effects in the perception of print: A comment on Jordan, Patching and Thomas. Cognitive Neuropsychology, 20, 73-80.

Nazir, T., Ben-Boutayab, N., Decoppet, N., Deutsch, A., \& Frost, R. (2004). Reading habits, perceptual learning, and the recognition of printed words. Brain and Language, 88, 294-311.

Nazir, T. A., O'Regan, J. K., \& Jacobs, A. M. (1991). On words and their letters. Bulletin of the Psychonomic Society, 29, 171-174.

Nicholls, M. E. R., \& Wood, A. G. (1998). The contribution of attention to the right visual field advantage for word recognition. Brain and Cognition, 38, 339-357.

Nuthmann, A., Engbert, R., \& Kliegl, R. (2005). Mislocated fixations during reading and the inverted optimal viewing position effect. Vision Research, 45(17), 2201-2217.

O’Regan, J. K. (1990). Eye movements and reading. In E. Kowler (Ed.), Eye movements and their role in visual and cognitive processes (pp. 395-453). Amsterdam: Elsevier.

O'Regan, J. K., \& Jacobs, A. M. (1992). Optimal viewing position effect in word recognition: A challenge to current theory. Journal of Experimental Psychology: Human Perception and Performance, 18, 185-197.

O'Regan, J. K., Levy-Schoen, A., Pynte, J., \& Brugaillère, B. (1984). Convenient fixation location within isolated words of different length and structure. Journal of Experimental Psychology: Human Perception and Performance, 10, 250-257.

Pollatsek, A., Bolozky, S., Well, A. D., \& Rayner, K. (1981). Asymmetries in the perceptual span for Israeli readers, Brain \& Language, 14, 174-180.

Pynte, J. (1996). Lexical control of within-word eye movements. Journal of Experimental Psychology: Human Perception and Performance, 22, 958-969.

Radach, R., \& McConkie, G. W. (1998). Determinants of fixation positions in words during reading. In G. Underwood (Ed.), Eye guidance in reading and scene perception (pp. 77-100). Oxford: Elsevier.

Radach, R., Reilly, R., \& Vorstius, C. (2004). Causes and consequences of the preferred viewing position in reading. Talk presented at the Sixth European Workshop on Language Comprehension, Oleron, France. 
Rayner, K. (1979). Eye guidance in reading: Fixation location within words. Perception, 8, 21-30.

Rayner, K. (1986). Eye movements and the perceptual span in beginning and skilled readers. Journal of Experimental Child Psychology, 41, 211-236.

Rayner, K. (1998). Eye Movements in Reading and Information Processing: 20 Years of Research. Psychological Bulletin, 124(3), 372-422.

Rayner, K., Liversedge, S. P., \& White, S. J. (2006). Eye movements when reading disappearing text: the importance of the word to the right of fixation. Vision Research, 46(3), 310-323.

Rayner, K., Sereno, S. C., \& Raney, G. E. (1996). Eye movement control in reading: A comparison of two types of models. Journal of Experimental Psychology: Human Perception and Performance, 22(5), 1188-1200.

Rayner, K., Slattery, T. J., \& Bélanger, N. N. (2010). Eye movements, the perceptual span, and reading speed. Psychonomic Bulletin \& Review, 17, 834-839.

Rayner, K., Yang, J., Castelhano, M., \& Liversedge, S.P. (2011). Eye movements of older and younger readers when reading disappearing text. Psychology \& Aging, 26, 214-223.

Reichle, E. D., \& Laurent, P. (2006). Using reinforcement learning to understand the emergence of “intelligent” eye-movement behavior during reading. Psychological Review, 113, 390-408.

Reichle, E. D., Rayner, K., \& Pollatsek, A. (2003). The E-Z Reader model of eye movement control in reading: Comparisons to other models. Behavioral and Brain Sciences, 26, 445-526.

Shillcock, R.C. (2007). Eye movements and visual word recognition. In G. Gaskell (Ed.), The Oxford Handbook of Psycholinguistics (pp. 89-106). NY: Oxford University Press.

Shillcock, R., Ellison, T. M., \& Monaghan, P. (2000). Eye-fixation behaviour, lexical storage and visual word recognition in a split processing model. Psychological Review, 107, 824-851.

Siéroff, E. \& Riva, M. (2011). Attention and the identification of parafoveal words in school-age children and adults. Journal of Neurolinguistics, 24, 420-434.

Simola, J., Holmqvist, K., \& Lindgren, M. (2009). Right visual field advantage in parafoveal processing: Evidence from eye-fixation-related potentials. Brain and Language, 111, 101113. 
Slattery, T. J., Rayner, K. (2010). Eye movements and text legibility. Applied Cognitive Psychology, 24, 1129-1148.

Stevens, M., \& Grainger, J. (2003). Letter visibility and the viewing position effect in visual word recognition. Perception \& Psychophysics, 65 (1), 133-151.

Vitu, F. (2003). The basic assumptions of E-Z Reader are not well-founded. Behavioral and Brain Sciences, 26, 506-507.

Vitu, F., Lancelin, D., \& d'Unienville, V. M. (2007). A perceptual-economy account for the inverted-optimal viewing position effect. Journal of Experimental Psychology: Human Perception and Performance, 33, 1220-1249.

Vitu, F., O'Regan, J. K., \& Mittau, M. (1990). Optimal landing position in reading isolated words and continuous text. Perception \& Psychophysics, 47, 583-600.

Vitu, F., McConkie, G. W., Kerr, P., \& O’Regan, J. K. (2001). Fixation location effects on fixation durations during reading: an inverted optimal viewing position effect. Vision Research, $41(25-26), 3513-3533$.

Whitney, C. (2001). How the brain encodes the order of letters in a printed word: The SERIOL model and selective literature review. Psychonomic Bulletin \& Review, 8, 221-243.

Whitney, C., \& Cornelissen, P. (2005). Letter-position encoding and dyslexia. Journal of Research in Reading, 28, 274-301.

Whitney, C., \& Lavidor, M. (2004). Why word length only matters in the left visual field. Neuropsychologia, 42, 1680-1688.

Williams, R. S., \& Morris, R. K. (2004). Eye movements, word familiarity, and vocabulary acquisition. European Journal of Cognitive Psychology, 16, 312-339.

Zoccolotti, P., De Luca, M., Di Pace, E., Gasperini, F., Judica, A., \& Spinelli, D. (2005). Word length effect in early reading and in developmental dyslexia. Brain and Language, 93, 369373. 


\section{AUTHORS' NOTE}

The authors thank Murièle Brand-D'abrescia and Céline Descottes for their participations in this research project. Support for this research was partly provided by a grant from the "Conseil Régional PACA" to the first author and by an APN Research Fellowship from the CNRS to the first author. Correspondence should be addressed to Stéphanie Ducrot, Laboratoire Parole et Langage, Aix-Marseille Université \& CNRS, 5 avenue Pasteur, 13100 Aix-en-Provence cedex 1, France, or via e-mail to stephanie.ducrot@univ-amu.fr. 


\section{FOOTNOTES}

1. Whitney and Lavidor (2004) provided an alternative view suggesting that perceptual learning occurs in the right hemisphere in order to invert the LVF activation pattern through lateral inhibition, in such a way that letters on the left inhibit letters on the right. As acuity increases for the final letters in the LVF, lateral inhibition becomes insufficient to create a smoothly decreasing spatial gradient. If the correct activation pattern for an LVF word cannot be attained automatically through (bottom-up) perceptual learning, attention is needed to obtain the correct activation gradient.

2. In a recent paper, Engbert and Krügel (2010) demonstrated that readers use prior task-specific knowledge about the probability distribution of target distances for optimal target localization on the basis of Bayesian saccade planning. Note that Engbert and Krügel's mathematical model is the first quantitative model of the saccadic range error; it makes explicit assumptions about the underlying visual and oculomotor processes generating the effect.

3. Several other models that assume parallel encoding of letters within words and use a relativeposition coding scheme, such as the self-organizing lexical acquisition and recognition (SOLAR) model (Davis, 1999), the open bigram model (Grainger \& van Heuven, 2003), the overlap model (Gomez, Ratcliff, \& Perea, 2008), and the spatial coding model (Davis, 2010), could account for visual word recognition in children, in particular by specifying how automatic orthographic processing is mastered in learning to read (see Lété \& Fayol, in press).

4. Manulex is a computerized lexical database that provides frequency-based lists of nonlemmatized and lemmatized words compiled from the 1.9 million words found in the main French primary school reading books.

5. This font was chosen because it is non-proportional, meaning that all characters are of equal width, thus ensuring that the statistical probability of any given character attracting a fixation is equal. However, this font may be less familiar to readers than other fonts used in schoolbooks and 
may therefore be harder to read. Whatever the case may be, processing difficulty due to font type should be equal for all children.

6. Note that in both of the present experiments, once the stimulus appeared, participants could move their eyes.

7. The grade recoding was chosen, firstly, in reference to the French elementary school curricula, which distinguish 3 levels: (1) preparatory course (CP), which is $1^{\text {st }}$ grade; (2) elementary course first and second years (CE1 and CE2), which are $2^{\text {nd }}$ and $3^{\text {rd }}$ grades; and (3) intermediate course first and second years (CM1 and CM2), which are $4^{\text {th }}$ and $5^{\text {th }}$ grades. Secondly, the number of subjects in each group and the variance were more homogeneous using 3 groups instead of 5.

8. Since saccade and eye-position data can be assumed to be dependent on the same processes, any variable that affects saccade size should also affect eye positioning.

9. Note that there was also a consistent relationship between the initial-fixation location and the initial-fixation duration for all children, with initial-fixation durations being the longest for initial fixations in the central region of the word, thereby showing an inverted-OVP (IOVP) effect. This IOVP effect was not modulated by word frequency (as found for adults in Nuthmann et al., 2005; Vitu et al., 2001, 2007). 


\section{Table 1}

Size and Direction of Initial Saccade (in characters), Latency (in ms), Initial Landing Position (in characters), Refixation Probability (in percentages) and Lexical Decision Time (in ms) as a Function of Stimulus Type, Word Frequency, Presentation Side, and School Grade (Experiment 1)

\begin{tabular}{|c|c|c|c|c|c|c|c|c|c|c|}
\hline \multirow[b]{2}{*}{ Stimulus } & \multicolumn{2}{|c|}{$\begin{array}{c}\text { Initial } \\
\text { saccade size }\end{array}$} & \multicolumn{2}{|c|}{ Latency } & \multicolumn{2}{|c|}{$\begin{array}{c}\text { Initial landing } \\
\text { position }\end{array}$} & \multicolumn{2}{|c|}{$\begin{array}{l}\text { Refixation } \\
\text { probability }\end{array}$} & \multicolumn{2}{|c|}{$\begin{array}{c}\text { Lexical } \\
\text { decision time }\end{array}$} \\
\hline & Left & Right & Left & Right & Left & Right & Left & Right & Left & Right \\
\hline \multicolumn{11}{|l|}{ GRADE 1} \\
\hline HF-Word & -4.2 & 3.2 & 193 & 189 & 3.0 & 1.4 & 93 & 88 & 2705 & 2650 \\
\hline LF-Word & -4.2 & 3.3 & 190 & 185 & 3.1 & 1.5 & 95 & 90 & 3184 & 2985 \\
\hline Pseudowords & -4.4 & 3.3 & 193 & 189 & 3.0 & 1.5 & 96 & 97 & 3446 & 3417 \\
\hline \multicolumn{11}{|l|}{ GRADE 2-3 } \\
\hline HF-Word & -4.4 & 3.5 & 173 & 169 & 2.9 & 1.6 & 78 & 69 & 1609 & 1555 \\
\hline LF-Word & -4.4 & 3.4 & 175 & 169 & 2.8 & 1.6 & 87 & 79 & 2063 & 1940 \\
\hline Pseudoword & -4.5 & 3.5 & 175 & 169 & 2.8 & 1.7 & 88 & 87 & 2333 & 2358 \\
\hline \multicolumn{11}{|l|}{ GRADE 4-5 } \\
\hline HF-Word & -4.7 & 3.9 & 152 & 146 & 2.7 & 2.0 & 66 & 60 & 1114 & 1014 \\
\hline LF-Word & -4.7 & 3.8 & 151 & 146 & 2.7 & 1.9 & 76 & 72 & 1289 & 1199 \\
\hline Pseudoword & -4.6 & 3.8 & 152 & 147 & 2.7 & 1.9 & 79 & 79 & 1401 & 1396 \\
\hline
\end{tabular}

Note. Initial saccade size and direction were measured with respect to the central fixation point. The initial landing position was measured with respect to the beginning of the word. 
Table 2

Refixation Probability (in percentages), Size and Direction of the Corrective Saccade (in characters), Landing Position (in characters) and Lexical Decision Time (in ms) as a Function of Stimulus Type, Word frequency, Presentation Side, and School Grade (Experiment 2)

\begin{tabular}{|c|c|c|c|c|c|c|c|c|c|c|c|c|c|c|c|}
\hline \multirow[b]{2}{*}{ Stimulus } & \multicolumn{5}{|c|}{ Refixation probability } & \multicolumn{5}{|c|}{ Refixation saccade size } & \multicolumn{5}{|c|}{ Lexical decision time } \\
\hline & $\mathrm{P} 1$ & $\mathrm{P} 2$ & P3 & $\mathrm{P} 4$ & P5 & $\mathrm{P} 1$ & $\mathrm{P} 2$ & $\mathrm{P} 3$ & P4 & P5 & P1 & $\mathrm{P} 2$ & P3 & $\mathrm{P} 4$ & P5 \\
\hline \multicolumn{16}{|l|}{ GRADE 1} \\
\hline HF-Word & 70.6 & 64.7 & 79.3 & 83.3 & 87 & 0.89 & 0.56 & -0.41 & -1.30 & -2.16 & 2393 & 2145 & 2317 & 2869 & 3159 \\
\hline LF-Word & 84.1 & 74.8 & 82.2 & 91.3 & 94.8 & 0.95 & 0.58 & -0.32 & -1.20 & -2.18 & 3719 & 3139 & 3190 & 3309 & 3851 \\
\hline Pseudowords & 95.1 & 86.9 & 83.1 & 90.5 & 93.5 & 0.83 & 0.43 & -0.27 & -1.35 & -2.21 & 3954 & 4209 & 4124 & 4128 & 4218 \\
\hline \multicolumn{16}{|l|}{ GRADE 2-3 } \\
\hline HF-Word & 54.1 & 39.2 & 54.5 & 65 & 70 & 1.13 & 0.99 & -0.13 & -1.35 & -2.21 & 1526 & 1421 & 1508 & 1719 & 1799 \\
\hline LF-Word & 76.4 & 46.7 & 62.3 & 77 & 81.3 & 0.90 & 0.79 & -0.33 & -1.38 & -2.28 & 1768 & 1670 & 1754 & 1933 & 2077 \\
\hline Pseudoword & 80.4 & 66.7 & 68.6 & 81.7 & 83.6 & 0.99 & 0.8 & -0.18 & -1.37 & -2.25 & 2308 & 2351 & 2325 & 2321 & 2473 \\
\hline \multicolumn{16}{|l|}{ GRADE 4-5 } \\
\hline HF-Word & 42.9 & 19.9 & 27.8 & 55.6 & 56.2 & 1.27 & 1.03 & 0.1 & -1.4 & -2.11 & 986 & 955 & 973 & 1068 & 1108 \\
\hline LF-Word & 57.6 & 25.8 & 35.4 & 65.6 & 65 & 1.37 & 0.95 & 0.1 & -1.3 & -2.2 & 1120 & 1056 & 1214 & 1288 & 1305 \\
\hline Pseudoword & 64.6 & 37.5 & 42.5 & 63.2 & 66.2 & 1.29 & 0.87 & 0.08 & -1.25 & -2.15 & 1390 & 1340 & 1331 & 1381 & 1382 \\
\hline
\end{tabular}

Note. Initial saccade size and direction were measured with respect to the central fixation point. The initial landing position was measured with respect to the beginning of the word. Standard deviations are shown in parentheses. 


\section{FIGURES CAPTIONS}

Figure 1. Description of the procedure used in Experiment 1.

Figure 2. Refixation probability and lexical-decision time as a function of initial-fixation position and lexicality in Experiment 2.

Figure 3. Refixation probability as a function of initial-fixation position and word frequency in Experiment 1 (Figure 3a) and Experiment 2 (Figure 3b). 